\title{
RESEARCH
}

Open Access

\section{Estimating the cost of implementing a facility and community score card for maternal and newborn care service delivery in a rural district in Uganda}

Anthony Ssebagereka* D, Rebecca Racheal Apolot, Evelyne Baelvina Nyachwo and Elizabeth Ekirapa-Kiracho

\begin{abstract}
Introduction: This paper aimed at estimating the resources required to implement a community Score Card by a typical rural district health team in Uganda, as a mechanism for fostering accountability, utilization and quality of maternal and child healthcare service.

Methods: This costing analysis was done from the payer's perspective using the ingredients approach over five quarterly rounds of scoring between 2017 and 2018. Expenditure data was obtained from project records, entered and analyzed in Microsoft excel. Two scale-up scenarios, scenario one (considered cost inputs by the MakSPH research teams) and scenario two (considering cost inputs based on contextual knowledge from district implementing teams), were simulated to better understand the cost implications of integrating the Community Score Card (CSC) into a district health system.

Results: The total and average cost of implementing CSC for five quarterly rounds over a period of 18 months were USD 59,962 and USD 11,992 per round of scoring, respectively. Considering the six sub-counties (including one Town Council) in Kibuku district that were included in this analysis, the average cost of implementating the CSC in each subcounty was USD 1998 per scoring round. Scaling-up of the intervention across the entire district (included 22 subcounties) under the first scenario would cost a total of USD 19,003 per scoring round. Under the second scaleup scenario, the cost would be lower at USD 7116. The total annual cost of scaling CSC in the entire district would be USD 76,012 under scenario one compared to USD 28,465 under scenario two. The main cost drivers identified were transportation costs, coordination and supervision costs, and technical support to supplement local implementers.

Conclusion: Our analysis suggests that it is financially feasible to implement and scale-up the CSC initiative, as an accountability tool for enhancing service delivery. However, the CSC design and approach needs to be embedded within local systems and implemented in collaboration with existing stakeholders so as to optimise costs. A comprehensive economic analysis of the costs associated with transportation, involvement of the district teams in coordination, supervision as well as provision of technical support is necessary to determine the cost-effectiveness of the CSC approach.
\end{abstract}

Keywords: Community score card, Cost analysis, Accountability, Health services, Maternal, Child health

\footnotetext{
* Correspondence: assebagereka@gmail.com

Department of Health Policy, Planning, and Management, Makerere University School of Public Health, New Mulago Hospital Complex, P.O. Box 7072, Kampala, Uganda
}

(c) The Author(s). 2021 Open Access This article is licensed under a Creative Commons Attribution 4.0 International License, which permits use, sharing, adaptation, distribution and reproduction in any medium or format, as long as you give appropriate credit to the original author(s) and the source, provide a link to the Creative Commons licence, and indicate if changes were made. The images or other third party material in this article are included in the article's Creative Commons licence, unless indicated otherwise in a credit line to the material. If material is not included in the article's Creative Commons licence and your intended use is not permitted by statutory regulation or exceeds the permitted use, you will need to obtain permission directly from the copyright holder. To view a copy of this licence, visit http://creativecommons.org/licenses/by/4.0/ The Creative Commons Public Domain Dedication waiver (http://creativecommons.org/publicdomain/zero/1.0/) applies to the data made available in this article, unless otherwise stated in a credit line to the data. 


\section{Introduction}

Social accountability interventions have been implemented widely, especially in resource-limited settings, to increase accountability and responsiveness to consumers of services by offering a platform for dialogue between consumers and service providers [1]. Their ultimate goal is usually to improve accountability and service delivery. Community Score Cards (CSCs) are one of the social accountability mechanisms that have been employed to improve accountability and responsiveness of service providers. They have been used as a mechanism to promote equity, access, and utilization of health services especially maternal and child health services $[2,3]$.

Community Score Cards improve transparency and community participation in decision making about service delivery by health facilities within their respective communities, which ultimately leads to improved quality of care from a clients' perspective [4-8]. The latter is attained through improved patient-provider relationships, improved performance of service providers (including better behaviors by service providers), and local authorities' improved responsiveness in terms of time and resources allocation $[1,9]$. Furthermore, better information sharing and communication during the CSC implementation catalyzes improvements regarding health workers' responsiveness to clients' service needs [10].

Current evidence and experiences from a number of interventions and pilot studies suggest that CSCs can be a useful tool for improving accountability and governance for health service delivery, quality, equity in access and utilization of health services [9, 11, 12]. However, the effectiveness of CSC initiatives is dependent on a number of factors, including the commitment and quality of local leadership to support the process, capacity of the implementing organization or institution, as well as characteristics of the local communities where the CSC process is implemented $[13,14]$.

Uganda is one of the countries where CSCs have been piloted and CSC pilots have contributed to an increase in service utilization indicators such as health facility delivery, family planning and immunization [1, 9, 15, 16]. However, these CSC pilots have been implemented in a few districts often by civil society organizations and have not culminated into a national scale-up. One major barrier to full implementation and scale-up of CSCs in Uganda has been limited financial resources to achieve sustainability and efficiency in CSC implementation [17]. Documented evidence on the cost of implementing a CSC initiative and the costs of social accountability more broadly is lacking, yet understanding the cost of implementing the CSC process is important in informing discussions and considerations for scale-up, sustainability, and institutionalization of such efforts.
Issues regarding accountability and social accountability are currently a topic of discussion in the policy arena, especially because of the renewed interest in attaining Universal Health Coverage (UHC) and the Sustainable Development Goals (SDGs). Therefore, a costing analysis is particularly timely in Uganda, where institutionalization of community Score Cards has not yet been realized despite several pilots. In Financial Year 2014/15, the Uganda Ministry of Health developed a national and facility-level score card for Reproductive, Maternal, Newborn, and Child Health (RMNCH) to promote transparency and accountability in service delivery [18]. This CSC provides a model that could be modified and used as a complement to the RMNCH Score Card, in order to add a community engagement component.

In this paper, we use the Future Health Systems' Community Score Card (FHS-CSC) case study to estimate the resource requirements, including the costs of implementing a CSC as a mechanism to foster social accountability in Maternal and Newborn health service delivery in a typical district health system in Uganda. While the costs themselves might be difficult to generalize in settings outside of Uganda, this paper also describes a costing process that can be adopted to estimate CSC implementation costs for similar contexts and can be adapted for costing of additional social accountability mechanisms.

\section{Methods \\ Study area}

This costing analysis was part of the FHS-CSC study in Kibuku, a rural district in Eastern Uganda. Kibuku district is a typical rural district setting in Uganda with a population of approximately 202,033 people and is approximated $200 \mathrm{~km}$ north-east of Kampala, the capital city of Uganda $[19,20]$. Kibuku district predominately has rural population, approximately 184,597 people, with low literacy levels [21] and whose occupations mainly include agriculture, petty trading, brick making, among others [22]. However, Kibuku district is a relatively new district established in 2010, and like several other rural districts, is still struggling to establish a robust system to deliver on its mandate. Kibuku district has 22 sub counties, 87 parishes, and 402 villages.

The FHS-CSC study was conducted in five sub-counties and one town council of Kibuku district. In Uganda, a sub-county is an administrative unit that is served by at least one Health Center III, usually with a catchment area of 30,000 people. Within each sub-county, are lower administrative units called parishes, which usually have a population of about 5000 residents. A town council is a peri-urban area in a rural district, and is resident to about 10,000 people. It's worthwhile noting that the median number of sub-counties in each district in Uganda is 11 
(and ranges between 5 to 28 sub counties) [23]. Kibuku district was selected because it represents a typical rural district in Uganda facing inadequate funding, inadequate human resources, low literacy levels, poor public service delivery and like many other districts, healthcare service provision is offered at decentralized level: that is, Health Centre I (community level/village health teams), Health Centre II, Health Centre III and Health Centre IV [24]. In Uganda, under the decentralization policy, health service delivery is a mandate of the district local government [25]. The district health system is superintended over by the district health office [26] that co-ordinates resource distribution, staff deployment and overall supervision of the health facilities including the district hospital, Health Center IV, IIIs and IIs [25]. Kibuku district has a total of 17 public sector health centers, but does not have a government hospital.

\section{Structure of the FHS-community score card study in Uganda}

The CSC entailed a series of facilitated meetings with and between Maternal and Newborn health service providers, users, district local government officials, political leaders, and other stakeholders. The meetings served as a platform for different stakeholders to share feedback regarding service delivery, identify service delivery and utilization challenges, and jointly work on generating solutions. Overall, the CSC involved a number of key processes as elaborated in Table 1. Further details on the FHS-CSC implementation in Uganda can be found in Ekirapa-Kiracho et al [16] and in Additional file 2.

During the implementation of the community score card, a number of adjustments in the mode of implementation were made, based on a learning-by-doing approach. These adjustments were mainly aimed at optimizing gains in efficiency and effectiveness. The implementation adjustments across the five scoring rounds are summarized in Additional file 1: Table S1.

\section{Costs: sources, measurement and perspective}

The cost analysis reported in this paper only refers to resources that were used in the implementation of the FHS- CSC intervention for the period June 2017 to December 2018. In this cost analysis, we identified the CSC activities that were implemented, the respective resources used to implement these activities, from which their respective costs were estimated. All costs were reported in United States Dollars (USD) during the year 2018, after making appropriate adjustments. Costs included in this analysis were estimated based on project accounting, financial and administrative records. The analysis adopted a provider's perspective (payer perspective); that is, only resources expended on implementation of the FHS-CSC were considered. This perspective was more appropriate for answering the main objective of this analysis - which was mainly to estimate the resource requirements for implementing a CSC within a district health system. A providers' perspective would also be useful in providing insights into resource or budget implications should Ministry of Health or government propose to integrate the program into the district health system or National Health Service delivery system (when scaling up). The value of time spent by the district staff and Makerere University School of Public health (MakSPH) research team was also considered when they contributed to implementation of the CSC.

Costs were classified into a) startup costs, and b) operational costs. The startup costs reflected the preparatory ground work that was carried out before round one of the CSC. These included costs for activities such as trainings, community sensitization, as well as stakeholder mobilization and buy in (Table 1). The operational costs, on the other hand, were incurred while running the CSC activities between round one and round five. The activities included community and facility scoring, interface meetings, district scoring, feedback meetings, stakeholder coordination, supervision, refresher trainings, stakeholder dissemination meetings, follow-up meetings and provision of technical support to the district team.

Program costs were identified and costing done based on the ingredients approach; where all program inputs were identified, quantified or measured, assigned monetary values and allocated [27-29]. Costs were classified by major activities as per the CSC implementation design. For each CSC activity, all costs incurred were identified and specified. The CSC intervention costs were broadly grouped into 10 categories shown in Table 2 .

\section{Estimating total costs}

Costs incurred during the CSC program implementation consisted of both fixed (semi-variable) costs and variable costs. Costs of coordination were semi-variable, in a sense that they had already been determined during the program budgeting process. However, other costs were variable in a sense that they were dependent on contextual aspects and field dynamics; for example, frequency of an activity - such as mobilization and sensitization, trainings and capacity building costs, among others. While the CSC outcome indicators included improvements in service utilization, we were unable to estimate the unit costs based on this indicator because the intervention did not have a control area to determine attribution of effect to the program. After obtaining the costs of the individual program inputs, these costs were aggregated to determine the total program cost over the intervention period [30]. We calculated the total and mean cost of implementing the CSC per round. The CSC 
Table 1 Key Community Score Card Implementation Processes

\begin{tabular}{|c|c|}
\hline Process & Elaboration of the process \\
\hline \multirow[t]{3}{*}{$\begin{array}{l}\text { Preparatory ground work } \\
\text { (planning meetings, } \\
\text { Community mobilization and } \\
\text { sensitization and } \\
\text { input tracking matrix preparation) }\end{array}$} & $\begin{array}{l}\text { Planning meetings: this involved meetings at district and sub-county levels with the political, technical, cc } \\
\text { nity leaders, health facility management and other stakeholders to solicit buy-in for the CSC project and s } \\
\text { intervention locations. It also involved development of training materials and training of the CSC facilitatc } \\
\text { coordinators. }\end{array}$ \\
\hline & $\begin{array}{l}\text { Community mobilization and sensitization: Through the district and sub-county political and technical lea } \\
\text { the participants for the community scoring were identified and mobilized. Radio spot messages were alsc } \\
\text { and patient charters printed and pinned up in different locations within the intervention area to sensitize } \\
\text { ferent stakeholders about their roles and responsibilities in } \mathrm{MNH} \text {. }\end{array}$ \\
\hline & $\begin{array}{l}\text { Input tracking matrix preparation: The health workers, District Health Team and technical support team fr } \\
\text { MakSPH conducted in-put tracking by looking at the standards required for different health facility levels } \\
\text { vis what was available on ground. They tracked; infrastructure, equipment, and staffing. This tracking was } \\
\text { ducted once at the beginning of the project. }\end{array}$ \\
\hline Health facility Scoring & $\begin{array}{l}\text { During the facility scoring, the health workers of the } 5 \text { selected health facilities listed their priority MNH } \\
\text { indicators; scored them using color codes and developed a facility score card as well as a work plan for } \\
\text { improvement. These were later presented in the interface meetings. This was repeated quarterly. }\end{array}$ \\
\hline
\end{tabular}

Community scoring

District scoring

Interface meetings

Dissemination

Monitoring and evaluation
Community scoring was done through 20 Focus Group Discussions (10-female, 10-male) with selected community members from all parishes in six sub counties in the intervention area. Each group comprised of 12 Focus Group Discussions (FGD) participants. In the first community score card meeting (round one) they identified and prioritized the indicators and then they scored the indicators using colors and developed work plans for improvement. In the subsequent rounds two and three they met and scored the indicators. In rounds four and five, the scoring was done during the interface meeting that happened at parish level.

The district scoring session was attended by 20 participants who discussed district performance as per the quarterly RMNCAH score card generated by $\mathrm{MoH}$ and developed a work plan for improvement. The DHT members also discussed $\mathrm{MNH}$ issues that had been raised by the communities during the scoring sessions.

In Round one of scoring, five interface meetings were held at sub-county level. During scoring rounds; $2,3,4$ and 5 , interface meetings were held at parish level totalling to 25 meetings in order to strengthen participation of community members. Participants at interface meetings included community members, health workers, DHT members, political and technical leaders, and other stakeholders.

During Round three of scoring, local council members started doing mobilization for the interface meetings in an attempt to improve attendance and participation of community members.

After each scoring round, stakeholders were briefed about findings from different sub-county and district Score Cards and workplans. The stakeholders included; district and sub-county political and technical leaders, health workers, civil society organisations (CSOs), community leaders, and Health Unit Management Committees (HUMCs)

The monitoring and evaluation activities comprised of feedback meetings and follow up meetings. After each scoring round, feedback meetings were arranged as a forum for facilitators from all the sub-counties to meet and discuss their scores and work plans. They also discussed, the gaps and challenges that had been identified and proposals to address them going forward. DHT members and the Makerere University School of Public Health (MakSPH) research team guided the feedback meetings. Fifteen [14] follow up meetings (one per Subcounty per scoring round for rounds one, two and three) were carried out with different sub-county councils and stakeholders who were responsible for oversight of implementation of agreed upon activities in the CSC work plans for their sub counties. round was selected as the unit of analysis due to its programmatic significance at implementation level; for example, in case a district wants to implement a given number of CSC rounds, findings from this study can readily inform planning and budgeting efforts for a successful activity. No discounting was done, because the implementation costs were incurred within a one-year time horizon. All costs were captured in Uganda Shillings (UGX) and reported in USD. A conversion rate of UGX 3600 per USD was used during the analysis based on the average exchange rate units over the period of implementation of this pilot program [31].

In order to examine the overall cost drivers, we calculated costs per CSC component, and conducted simulations for two scale-up scenarios, discussed in the following section below. Scenario one was proposed by, and from the perspective of the MakSPH research team, while the other scenario was from the District implementation teams considering no support from the MakSPH team. Subsequently, the two scenarios were rigorously discussed upon with regard to the possibilities of scaling the intervention to the entire district, and consensus was reached on having simulations of the two scenarios.

\section{Simulating CSC scale-up scenarios}

We simulated two scale up scenarios to demonstrate possible implications if the pilot were to be scaled-up to other 22 sub-counties, and also implemented in the entire Kibuku district over a period of one year beyond 
Table 2 CSC Costing Categories for the Start-up and Operational Costs

\begin{tabular}{|c|c|}
\hline Cost category & Description of the category \\
\hline Training & $\begin{array}{l}\text { Initial training costs included costs related to training of DHTs }{ }^{\mathrm{a}} \text {, implementation teams, } \mathrm{HUMCs}^{\mathrm{b}} \text { and } \\
\mathrm{VHTs}^{\mathrm{c}} \text {. } \\
\text { Refresher training costs included transport refund and refreshments provided to the participants } \\
\text { during the refresher training that occurred before each round of scoring. }\end{array}$ \\
\hline Mobilization and sensitization & $\begin{array}{l}\text { Costs related to mobilization and sensitization meetings held at district sub-county, parish, and com- } \\
\text { munity levels at the start of the project. Additional costs were incurred on media engagements in- } \\
\text { cluding talk-shows and radio spots, and design and printing of the patient charter. During the } \\
\text { implementation mobilization was done using a public address system and by members of the local } \\
\text { council leadership in round two, three and four. }\end{array}$ \\
\hline Coordination costs & $\begin{array}{l}\text { These captured costs incurred on allowances for core personnel for MakSPH ( } 50 \% \text { of the time for the } \\
\text { CSC coordinator) involved in initial planning and design, and allowances for coordinators from the } \\
\text { district and sub-county. } \\
\text { Other costs also included airtime for coordination of scoring activities. }\end{array}$ \\
\hline Supervision costs & $\begin{array}{l}\text { This category captured costs incurred on core personnel involved in providing technical support and } \\
\text { supervision from MakSPH and the District Health Team. Other costs included transport for regular } \\
\text { monitoring, supervision. }\end{array}$ \\
\hline Transport & Transport costs included all costs spent on transportation requirements \\
\hline Facilitation costs & Facilitation costs included all payments made to the facilitators of the CSC meetings \\
\hline Refreshments & $\begin{array}{l}\text { Costs on refreshments included all the costs incurred to provide meals and refreshments during the } \\
\text { meetings }\end{array}$ \\
\hline $\begin{array}{l}\text { Monitoring and evaluation costs, Feedback } \\
\text { meetings and sessions }\end{array}$ & $\begin{array}{l}\text { These costs included costs for the feedback and follow up meetings. The Costs incurred during these } \\
\text { sessions included: transport refunds or allowances for participants, and refreshments. }\end{array}$ \\
\hline Dissemination meetings. & $\begin{array}{l}\text { This comprised of costs incurred during the quarterly stakeholder meeting; refreshments and } \\
\text { transport refund for different stakeholders, coordinators and DHT for all the five scoring rounds. Each } \\
\text { dissemination meeting had an average of } 60 \text { participants. }\end{array}$ \\
\hline Stationery & This included all costs spent on stationery used during the CSC process \\
\hline
\end{tabular}

${ }^{a}$ DHT District Health Team: ${ }^{b} H U M C s$ Health Unit Management Committees:

${ }^{c} V H T$ s Village Health Teams

the period of the FHS project implementation. Scenario one reflects a hybrid system with both project and district support to implementation, while scenario two depicts a purely district led approach to implementation. Scenario one cost inputs were determined by the MakSPH research team (based on the expenditures and experiences of implementation of CSC rounds 3,4 and 5). The cost inputs into scenario two were decided on and agreed upon by the sub-county coordinators and District Health Team (based on their experiences of implementing the CSC process during the pilot phase). Hence, this reflects their contextual opinion about the costs they felt would be required to scale up/ implement, and fund the community score card under the district health system.

The scenarios aim to depict implications on overall cost when key cost drivers are adjusted to enhance efficiency and effectiveness. They also factor in feasibility and cost considerations as the main decision-making criteria that Ministry of Health officials and District Health Teams might use for decision-making regarding implementation and scale up of the CSC. For example, in scenario one, the participation of the MakSPH team was reduced to only the 3 days of the initial training and the costs for other meetings were reduced to reflect government per diem rates. While the project often paid a transport refund of UGX 30,000 (USD 8.3), the government rate was UGX 17,000 (USD 4.7). On the other hand, in scenario two, we eliminated all support from the MakSPH team, except for the initial training. It also substantially reduces the costs incurred for conducting of meetings by either dropping or lowering the per diems paid, shortening the meetings or piggy backing on other meetings. These are all commonly used practises in project led and district led programs that depict variations in implementation modalities and the costs there in.

The components of what was included in the scale up scenarios as well as explanations for inclusion or exclusion are shown in Table 3.

The CSC process comprises of four rounds of scoring in a year, done on a quarterly basis. The CSC scale-up costs for training, mobilization, facilitation and coordination allowances, and for each scenario were estimated, from which we computed the average start up and operational costs. We presented the average cost estimates for implementing a single scoring round as well as the projected annual costs for the four rounds of scoring. In addition, we also presented the estimates of CSC implementation in one sub-country and then scale up costs to 
Table 3 Parameters Used for Simulation of Community Score Card Scale-up Scenarios

\begin{tabular}{|c|c|c|c|}
\hline Cost inputs & $\begin{array}{l}\text { Costs included } \\
\text { in scenario one }\end{array}$ & $\begin{array}{l}\text { Costs included } \\
\text { in scenario two }\end{array}$ & Justification for inclusion \\
\hline Initial training & $\sqrt{ }$ & $\sqrt{ }$ & $\begin{array}{l}\text { Initial training will be required to impart the necessary skills in both scenario } 1 \\
\text { and } 2\end{array}$ \\
\hline Community mobilization & $\sqrt{ }$ & & $\begin{array}{l}\text { Community mobilization and sensitization will be required to equip the } \\
\text { community with information about the CSC but in scenario 2, only existing } \\
\text { meetings will be used and so no extra costs are included. }\end{array}$ \\
\hline $\begin{array}{l}\text { Stakeholder meeting at } \\
\text { subcounty level }\end{array}$ & $\sqrt{ }$ & & $\begin{array}{l}\text { Stakeholder meetings will be required for buy in. In scenario } 2 \text { this will be done } \\
\text { as part of another ongoing activity and so no extra costs are attached }\end{array}$ \\
\hline Mobilization & $\sqrt{ }$ & & $\begin{array}{l}\text { Local council chair persons will mobilize participants for the interface meetings } \\
\text { in scenario } 1 \text {; in scenario } 2 \text { they will do the mobilization without any payment }\end{array}$ \\
\hline Stationery & $\sqrt{ }$ & $\sqrt{ }$ & Stationery will be required for the scoring activities in both scenarios \\
\hline $\begin{array}{l}\text { Preparatory meeting at } \\
\text { subcounty level }\end{array}$ & $\sqrt{ }$ & & $\begin{array}{l}\text { Preparatory meetings will be held for half a day and will attract costs for break } \\
\text { tea and safari day allowance. In scenario } 2 \text { the meetings will be much shorter } \\
\text { about } 1 \text { hour and will not attract any financial costs. }\end{array}$ \\
\hline Health facility scoring & & & $\begin{array}{l}\text { Meetings will attract no additional costs in both scenarios since they will be } \\
\text { done during routine facility review meetings }\end{array}$ \\
\hline $\begin{array}{l}\text { Scoring and interface } \\
\text { meetings }\end{array}$ & $\sqrt{ }$ & $\sqrt{ }$ & $\begin{array}{l}\text { Safari day allowance of USD } 5 \text { will be paid to facilitators in scenario } 1 \text { while only } \\
\text { transport refund of USD } 2.77 \text { will be paid in scenario } 2 \text {. }\end{array}$ \\
\hline $\begin{array}{l}\text { Feedback meeting at } \\
\text { subcounty }\end{array}$ & & & $\begin{array}{l}\text { Feedback will be done after each interface meeting so that no extra costs are } \\
\text { incurred in both scenarios }\end{array}$ \\
\hline $\begin{array}{l}\text { Stakeholder dissemination } \\
\text { meeting }\end{array}$ & & & $\begin{array}{l}\text { Dissemination of CSC findings will be done during routine quarterly joint } \\
\text { stakeholder meetings at the district and subcounty council meetings so that no } \\
\text { extra costs are incurred in both scenarios }\end{array}$ \\
\hline $\begin{array}{l}\text { Sub-county coordinator } \\
\text { and Co-coordination costs }\end{array}$ & $\sqrt{ }$ & $\sqrt{ }$ & $\begin{array}{l}\text { The subcounty coordinators will receive a safari day allowance for their } \\
\text { facilitation in both scenarios }\end{array}$ \\
\hline $\begin{array}{l}\text { DHT members supervision } \\
\text { costs }\end{array}$ & $\sqrt{ }$ & & $\begin{array}{l}\text { The DHT members will receive a safari day allowance for their facilitation in } \\
\text { scenario } 1 \text { while in scenario } 2 \text {, supervision will be done by the subcounty } \\
\text { coordinators }\end{array}$ \\
\hline
\end{tabular}

the entire district which comprises of 22 subcounties. During the simulation, we did not adjust for inflation or discount any costs since the implementation costs were incurred within a one-year time horizon.

In our analysis, we took into account the following assumptions:

1 Implementation of the CSC processes was consistent with the protocol guidance given to the implementing teams to achieve evenly distributed optimum outcomes across the subcounties.

Furthermore, it was assumed that Kibuku district represented structures, context and operations of a typical rural resource-constrained district.

2 A constant number of people would attend the scoring, preparatory and feedback meetings held at the district and subcounty offices in all the scoring rounds.

3 The payments made to the MakSPH team represented the typical costs that would be incurred by a technical implementing partner for the CSC process.

4 All expected district and subcounty local government meetings would happen as scheduled hence the health facility scoring would be conducted during routine facility review meetings and the district implementation teams (comprised of the DHT, the district and sub-county coordinators) made rational input based on the district local government implementation context regarding implementation of the CSC.

5 The district comprised of the total number of sub counties (22 sub counties for Kibuku) and the average cost of implementation was similar across all subcounties.

This costing analysis complies with the consolidated health economic evaluation reporting standards (CHEE RS) checklist, see Additional file 1: Table S3.

\section{Results}

Summary costs for the CSC implementation processes The overall total cost of implementing the CSC intervention in the five sub counties and one town council of Kibuku district was USD 59,962 with an average cost per scoring round of USD 11,992. The average cost of conducting the CSC per subcounty was USD 9710, while the average cost per round per sub-county was USD 
1998. It is important to note that the implementation modalities were the same across all sub counties hence the costs of implementation were generally comparable across the subcounties. Expenditures for the different CSC implementation activities that include; preparatory ground work (planning, community sensitization and mobilization and input matrix tracking), health facility scoring, community scoring, district scoring, interface meeting, dissemination and monitoring and evaluation are presented in Table 4.

The highest implementation costs were incurred during monitoring and evaluation, preparatory ground work and interface meetings. The monitoring and evaluation phase included follow-up meetings at district and subcounty levels as well as feedback meetings with the CSC implementation team. However, substantial costs were also attributed to allowances for per diem and transportation as well as refreshments as highlighted in Additional file 1: Table S2. The costs for the community scoring decreased in the 4th and 5th round because the community scoring and interface meetings were combined. However, additional costs were attributed to the interface meeting during both rounds, as compared to the community scoring meetings, and thus, the interface meetings had higher costs compared to the community scoring. On the other hand, the costs of implementing district scoring and dissemination meeting in round four increased because there was an increase in the number of participants at these meetings. Lastly the monitoring and evaluation costs dropped in round five because we did not conduct follow up meetings, in order to optimize the limited resources available. Details of the CSC implementation costs are presented in Additional file 1: Table S2.

\section{Implementation costs of the CSC}

Preparatory ground work was carried out before round one of the CSC and included costs for trainings of the DHT and supervisors/coordinators on CSC, community sensitization, and stakeholder mobilization, coordination, transport, facilitation, stationery and refreshments. Thus, the total CSC start-up costs were USD 11,423. Trainings had the highest proportion of start-up costs, accounting for up to $38 \%$ (USD 4300) of the total start-up costs, while stationery costs contributed the lowest proportion. Implementation costs are summarised in Table 5.

Overall, the highest costs were incurred on transportation of technical teams (One third of the total program costs were attributed to transportation for the technical teams), participants to and from the meeting venues, facilitators and supervisors of meetings. Round one had the highest costs because it was the first scoring round and therefore the support from MakSPH was more intense, with more members of the team which also gave rise to higher transport costs.

Supervision incurred the second highest costs and this could be attributed to the higher per diem costs for the MakSPH team. Coordination costs were also high, with a lot of activities happening at the community, sub-county, and district in addition to the technical coordination support from MakSPH. The CSC intervention involved a lot of activities and meetings, as detailed in Table 2, and therefore high-level coordination was key to its success. On the other hand, expenditures on stationery were the lowest, with most of the costs being incurred during rounds one and two. The costs of stationery gradually declined in rounds 3,4 and 5 mainly because the community scoring and interface meeting was combined and low-cost materials used to lower implementation costs.

Based on the total number of administrative units (subcounties in this case) in the district, several CSC scale-up scenarios were later developed, as shown in Table 6.

\section{Scale up scenarios: sub-county and district level}

Two CSC scale-up scenarios were simulated: the first one took into account cost inputs based on experiences of the MakSPH team in providing technical support to the district teams, while the second one took into consideration cost inputs from the district CSC implementation teams,

Table 4 Summary of costs for implementation of the Community Score Card processes

\begin{tabular}{|c|c|c|c|c|c|c|c|c|}
\hline Activities & Startup costs & Round one & Round two & Round three & Round four & Round five & Total & \%allocation \\
\hline Preparatory groundwork & 11,413 & & & & & & 11,413 & $19 \%$ \\
\hline \multicolumn{9}{|l|}{ Operational costs } \\
\hline Health facility scoring & & 683 & 911 & 851 & 1189 & 917 & 4550 & $8 \%$ \\
\hline Community scoring & & 1245 & 1473 & 1410 & 956 & 843 & 5926 & $10 \%$ \\
\hline District scoring & & 663 & 660 & 781 & 1138 & 813 & 4055 & $7 \%$ \\
\hline Interface meetings & & 2140 & 2138 & 2804 & 2404 & 2231 & 11,717 & $20 \%$ \\
\hline Dissemination & & 1488 & 1729 & 1704 & 2247 & 1870 & 9036 & $15 \%$ \\
\hline Monitoring and Evaluation & & 3065 & 2960 & 2702 & 2669 & 1869 & 13,265 & $22 \%$ \\
\hline Total & 11,413 & 9283 & 9870 & 10,252 & 10,602 & 8542 & 59,962 & $100 \%$ \\
\hline
\end{tabular}


Table 5 CSC implementation costs (USD)

\begin{tabular}{lllllllll}
\hline Cost inputs & Startup costs & Round one & Round two & Round three & Round four & Round five & Total & \% allocation \\
\hline Coordination & 1333 & 1014 & 1409 & 1820 & 2167 & 1778 & 9521 & $16 \%$ \\
Supervision & 1055 & 1333 & 2333 & 1607 & 2417 & 1597 & 10,342 & $17 \%$ \\
Training & 4300 & - & - & - & - & - & 4300 & $7 \%$ \\
Mobilization & 1722 & 712 & 671 & 756 & 765 & 765 & 5391 & $9 \%$ \\
Transportation & 1763 & 4364 & 3634 & 4043 & 3566 & 2683 & 20,053 & $33 \%$ \\
Facilitation & 806 & 853 & 804 & 992 & 805 & 954 & 5213 & $9 \%$ \\
Refreshments & 376 & $\mathbf{7 5 7}$ & $\mathbf{7 6 8}$ & 818 & 739 & 625 & 4084 & $\mathbf{7} \%$ \\
Stationery & 57 & 250 & 250 & 217 & 144 & 139 & 1058 & $2 \%$ \\
Total & $\mathbf{1 1 , 4 1 3}$ & $\mathbf{9 2 8 3}$ & $\mathbf{9 8 7 0}$ & $\mathbf{1 0 , 2 5 2}$ & $\mathbf{1 0 , 6 0 3}$ & $\mathbf{8 5 4 1}$ & $\mathbf{5 9 , 9 6 2}$ & $\mathbf{1 0 0 \%}$ \\
\hline
\end{tabular}

based on local contextual knowledge. For each scenario (Table 6), we present the startup and operational costs for a single scoring round per sub-county and for the entire district (22 sub-counties in the entire district). We also present the annual costs of CSC implementation (four scoring rounds per year) per sub-county and per district.

\section{Scenario one}

The average cost of implementation of a single scoring round per sub-county was USD 1716 in Scenario one (with average startup costs of USD 1542 and operational costs of USD 174.4). More strikingly, the total cost of a single scoring round for the entire district was USD 19,
003. The annual cost of CSC implementation was USD 76,012 in Kibuku district over the four rounds.

\section{Scenario two}

On the other hand, the average cost of implementation of a single scoring round per sub-county was even lower in scenario two at USD 1002 (with startup costs USD 954 and operational costs of USD 48) compared to the earlier scenario. In addition, the total cost of a single scoring round for the entire district was much lower at USD 7116 compared to scenario one, while the annual cost of CSC implementation in Kibuku district over the four rounds was USD 28,465 .

Table 6 Costs of Community Score Card Scale-up in Kibuku district by scenario

\begin{tabular}{|c|c|c|c|c|c|c|c|c|}
\hline \multirow[t]{3}{*}{ Cost inputs } & \multicolumn{4}{|c|}{ Scenario one } & \multicolumn{4}{|c|}{ Scenario two } \\
\hline & \multicolumn{2}{|c|}{$\begin{array}{l}\text { Single round cost } \\
\text { (USD) }\end{array}$} & \multicolumn{2}{|c|}{$\begin{array}{l}\text { Annual cost }{ }^{\mathbf{b}} \\
\text { (USD) }\end{array}$} & \multicolumn{2}{|c|}{$\begin{array}{l}\text { Single round cost } \\
\text { (USD) }\end{array}$} & \multicolumn{2}{|c|}{$\begin{array}{l}\text { Annual } \operatorname{cost}^{\mathbf{b}} \\
\text { (USD) }\end{array}$} \\
\hline & $\begin{array}{l}\text { Sub- } \\
\text { county }^{a}\end{array}$ & District & $\begin{array}{l}\text { Sub- } \\
\text { county }\end{array}$ & District & $\begin{array}{l}\text { Sub- } \\
\text { county }^{a}\end{array}$ & District & $\begin{array}{l}\text { Sub- } \\
\text { county }\end{array}$ & District \\
\hline \multicolumn{9}{|l|}{ Startup costs } \\
\hline Initial training & 949 & 6432 & 3794 & 25,728 & 949 & 5821 & 3794 & 23,283 \\
\hline Community mobilization & 270 & 1625 & 6500 & 6500 & - & - & - & - \\
\hline Stakeholder meeting (sub-county level) & 311 & 6844 & 1244 & 27,378 & - & - & - & - \\
\hline Stationery & 12 & 264 & 48 & 1056 & 6 & 244 & 22 & 978 \\
\hline Sub-total - startup costs & 1542 & 15,165 & 11,587 & 60,661 & 954 & 6065 & 3817 & 24,261 \\
\hline \multicolumn{9}{|l|}{ Operational costs } \\
\hline Mobilization & 25 & 550 & 100 & 2200 & - & - & - & - \\
\hline Preparatory meeting at sub-county level & 64 & 1406 & 256 & 5622 & - & - & - & - \\
\hline $\begin{array}{l}\text { Scoring and interface meetings (per diem for } \\
\text { facilitators) }\end{array}$ & 40 & 880 & 160 & 3520 & 22 & 489 & 89 & 1956 \\
\hline District and sub-county coordination allowance & 20 & 440 & 80 & 1760 & 20 & 440 & 80 & 1760 \\
\hline Stationery & 6 & 122 & 22 & 489 & 6 & 122 & 22 & 489 \\
\hline DHT members supervision costs & 20 & 440 & 80 & 1760 & - & - & - & - \\
\hline Sub-total - Operational costs & 175 & 3838 & 698 & 15,351 & 48 & 1051 & 191 & 4205 \\
\hline Grand total & 1716 & 19,003 & 12,285 & 76,012 & 1002 & 7116 & 4008 & 28,465 \\
\hline
\end{tabular}

${ }^{a}$ Average costs reported per sub-county ${ }^{\mathrm{b}}$ Annual costs reported for CSC implementation reported over for quarters 


\section{Discussion}

In this paper, we set out to estimate the cost of implementing a facility-based and community-based Score Card that was aimed at improving social accountability in maternal and new-born health service delivery for a typical rural district in a resource-limited setting. To the best of our knowledge, this is one of the first papers in low-income settings like Uganda to estimate the cost of implementing CSC. Whereas it is undisputable that social accountability mechanisms and approaches play an important role in improvement of service delivery, strengthening of governance systems, empowerment of citizens, and improvement of outcomes, there was little information regarding the cost of implementing and scaling these impactful approaches within the district setting $[1,9,32]$. Our paper provides the much-needed information on the cost of implementing a CSC in a resource limited setting and offers more reflections on the key cost parameters to watch out for during implementation as well as suggestions for cost reduction. The overall total cost of implementing the CSC intervention in five sub counties and one town council in Kibuku district was USD 59,962. Furthermore, the average cost of CSC implementation per scoring round per sub-county was USD 1998. Unfortunately, there is very limited data on different implementation modalities and the cost of implementation of CSCs and so we could not compare these costs with other similar studies.

The highest CSC implementation costs were incurred during monitoring and evaluation activities, interface and dissemination meetings, and during preparatory ground work. These activities had a fairly high number of stakeholders who received per diem as well as allowances for transport, meals and refreshments. Experience from the CSC implementation shows that expenditures on items such as transport and refreshments could not be avoided in this typical district setting since it was observed that stakeholders are accustomed to receiving allowances for attending meetings. Thus, it was difficult to expect them to participate in the project activities without receiving any allowances (Additional file 2). Indeed, CSC implementation often involves several steps which end up being resource intensive both in terms of time and human resource costs [33, 34] (Additional file 3). However, we noted that there is a window of opportunity for reducing the number of stakeholders and amount of allowances they were paid, which would contribute to a reduction in the overall cost of CSC implementation as observed in the simulations for scenario two.

With regard to operational costs, transportation, supervision and coordination attracted the highest costs overall. This was mainly attributed to the higher costs of transportation and per diem for the capital city-based MakSPH technical support team which remained actively engaged throughout the five rounds of scoring. The CSC intervention involved a lot of activities and therefore high-level coordination was a key component to its success and yet the busy work schedules of the DHT members limited their early involvement in the implementation.

On the other hand, there were much lower costs incurred in conducting the facility and district meetings. This could be attributed to the much smaller number of meetings and participants in these meetings. Similarly, the main CSC activities, such as the community scoring, attracted relatively lower costs because the project team deliberately lowered most of the respective costs, while other cost items like refreshments and transport refund for community participants during scoring rounds three, four and five were eliminated. This adjustment was made having realized that providing such facilitation raised the monetary expectations (in a way, setting a precedent) that are difficult to sustain. Furthermore, it undermines the spirit of voluntarism and participation that are major foundations for primary health care. However, it is important to note that such decisions are not always welcomed by community members, mainly because they often expect monetary compensation at the end of meetings [25]. Further reduction in costs were attributed to the joining of the scoring and interface meetings, with the scoring requiring less time towards the later implementation stages.

Alternatively, interface meetings had higher costs compared to the community scoring and the district scoring. This could be attributed to the higher number of interface meetings ( 25 meetings) and related costs (refreshments, transport allowances and per diem for facilitation and supervision) per quarter between rounds two and five. Whereas, broad stakeholder engagement is desired to maximize outcomes from the CSC processes, inclusion of a wide range of stakeholders can be timeconsuming as well as cost prohibitive [35]. Therefore, careful consideration and inclusion of individuals, especially those that add substantial input to the core process is required to optimize resources and outcomes.

When compared to the quarterly unconditional grants from the central government of USD 833 received by each sub-county from which they are required to budget for health, the CSC operational costs appear affordable since under scenario two, it amounts to only $5 \%$ of the subcounty budget. This argument is also supported by findings from a similar study done in Satara district in India that introduced social accountability mechanisms and found that these CSC activities were quite affordable at district level, accounting for even less than $1 \%$ of the district total budget, and yet resulted in substantial achievements including behavior and institutional changes as well as concrete outcomes [36]. Similar actions could be taken 
in Uganda especially if the CSC activities are implemented as part of an integrated package of services. They could also take advantage of the recently launched constituency assembly meetings (Baraza's) which are community advocacy forums for enhancing political and performance accountability [37, 38].

The findings from the simulations show that when CSC activities are implemented and funded largely by local stakeholders, the costs are much lower compared to circumstances where they are implemented and funded by external partners [16]. Nevertheless, careful attention should also be paid to critical aspects that might influence differences in the outcomes between implementation sites. For example, in scenario one, more financial incentives are given to the implementation teams from the district. From our CSC pilot program, we learnt that these are critical for a successful implementation of the CSC activities. The incentives provided to the implementing teams vary depending on the cadre level, as well as local contextual aspects. Some of these incentives include competitive safari day allowances as well as transport refund and refreshments. In the absence of these incentives, the implementing teams from the district could be demotivated and they may not carry out the expected activities, or they may implement them sub-optimally. The reduced incentives in scenario two could therefore potentially lead to poorer outcomes in terms of participation, impact, as well as continuity of the CSC activities.

That said, we also recognize that the effect of the CSCs also depends on the capacity of the implementing teams at the district and their familiarity with the CSC processes. In scenario one, the district health team was to provide oversight to the sub-county teams, whereas in scenario two the sub-county leaders would provide oversight. Since the district health team generally has more qualified and experienced staff, it is reasonable to assume that their involvement would also lead to more effective implementation of the CSCs and subsequently improved outcomes. Conversely, it is also important to note that implementation in both scenarios could also be influenced by non-financial contextual aspects like good governance and strong leadership, including selfdriven teams that desire nothing but excellence, implying that in both scenarios, performance and outcomes could turn out to be very good primarily as a result of the existing intrinsic motivation coupled with other positively reinforcing contextual factors.

High costs of implementation are one of the factors that constrain the implementation and scale-up of hitherto effective interventions across many settings, and more so for resource constrained settings. Strategies therefore need to be adopted to minimize costs, including identifying and minimizing use of inputs that attract high costs. In doing this, however, caution ought to be taken to ensure that essential and key programme inputs are not eliminated leading to ineffective implementation. Other strategies to minimize costs may include limiting allowances in the initial phases (start-up), encouraging community effort and participation, having joint dissemination meetings and building local or district capacity so as to limit technical support to only critical programme areas where local capacity may still be lacking or reasonably insufficient. The community members may be more willing to participate without expecting payment if the scorecard process leads to improved service delivery whereas the high initial or start-up costs incurred in building local capacity would be expected to gradually decline as the project design is further modified and adapted to the local context [1]. Joint meetings however may be affected by sudden cancellations by some of the partners; secondly the agenda papers for the joint meetings may not allow sufficient time to have detailed discussion of issues and challenges identified during the scoring meetings [12] (Additional file 2). That said, it is important to note that the overall cost of CSC implementation is highly dependent on the specific CSC design, context, location, scope, scale, and these factors indeed influence successful implementation, achievement of desired outcomes and the possibility of scale-up [39].

\section{Methodological considerations}

Some of the limitations of this work include the fact that we have simulated the costs for the scale-up scenarios, having not had the opportunity to capture actual implementation costs over this geographical scope, and hence the costs proposed should be interpreted with caution. However, during the simulation, we attempted to address this gap by incorporating the local contextual knowledge and learnings from implementation of the pilot as well as knowledge of implementation of social accountability programs within the district system, into the cost analysis to better adapt the estimates as close as possible to reality. On the other hand, the scale-up scenarios are based on costs from one rural district. This might affect the generalizability of our findings to other districts in Uganda especially those that have stronger governance structures/systems and those located in urban settings with relatively more funding from the central government or donor funded projects. We assert that for districts with settings that have more developed systems and are better resourced, the CSC programs there may incur more expenses in payment of per diem costs, supervision and coordination costs for the staff involved in the CSC activities compared to those in the rural under-resourced settings. In addition, districts with very poor road networks, especially during the rainy seasons, will also incur much higher transport costs [40]. However, Kibuku district is typical of other rural 
districts which are still building and setting up local structures, are under resourced, have weak infrastructure, and wide spread poverty $[41,42]$. It therefore arguably represents a resource limited context which most districts in Uganda face and the East African region at large. In fact, $75 \%$ of the households in Uganda are in the rural areas, hence further suggesting representativeness of the geographical scope in this study [19].

Additionally, the CSC processes involves a large number of activities and so accurately attributing the costs and cost savings is always a challenge. However, it's important to note that resource optimization and economies of scale can be attained as the number of sub-counties covered by the CSC increase, although that would require a higher level of organization and coordination. Whereas the societal perspective is widely considered as being the most comprehensive to reflect the decision maker's perspective [43, 44], our cost analysis focused on only the provider's perspective. Although this could affect generalizability of the results and the overall estimated costs of scale up, we think that the effect is likely to be minimal since the additional opportunity costs (that would have been captured as part of the computed societal costs) are likely to be minimal due to the low earnings of these rural populations. That notwithstanding, the societal perspective not only focuses on broad cost aspects of the society's total welfare, but also allows capturing of the value of all changes in resources used as a consequence of a given intervention(s) [45].

The implementation period for the study of one year was also too short for us to comprehensively capture the actual scale-up costs. To address this gap, we used simulations to estimate the CSC scale-up costs within the entire Kibuku district. Future studies could do simulations that reflect the nation-wide cost of CSC implementation putting in consideration several key factors such as the size of different districts (in terms of geography and population), availability of district staff to implement/supervise the CSC activities, existence of and partnerships with civil society, degree of urbanization and variation in socio-economic status. Lastly since we did not consider the effects of the program and yet CSC programs have had mixed effects [5, $9,15,33,34]$, future research could also consider conducting a comprehensive economic evaluation to estimate the net cost implications for CSC implementation in low- and middle-income countries, so as to inform ongoing efforts to incorporate CSC and other social accountability mechanisms into health programming. These will ultimately support financing for CSC to foster improvements in quality of maternal and new-born health services as well as outcomes in resource limited settings like Uganda.

\section{Conclusion}

Our paper is one of the few that attempt to estimate the cost of implementing CSC implementation in resource limited settings. Furthermore, our analysis has also provided simulations for costs that may be required to implement a CSC at scale, at the different levels of administration or service delivery - the sub-county and the district. The overall cost of implementing the CSC intervention in five subcounties and one town council in Kibuku district was USD 59,962. The average cost of implementing the CSC per scoring round per subcounty was USD 1998. The main cost drivers were transportation costs, coordination and supervision costs to support the technical capacity of the local implementers. The other cost drivers included transport refunds and provision of refreshments and meals for the dissemination and monitoring and evaluation meetings.

Our analysis suggests that it is financially feasible to implement and scale-up the CSC initiative, as an accountability tool for enhancing service delivery. However, the CSC approach and implementation design must be one that is contextual, optimizes costs, including ensuring adequate involvement of local communities and stakeholders. Under the scale-up simulations, scenario two (considering cost inputs from the district implementation teams) was noted to have the lowest CSC implementation costs with an estimated annual CSC implementation cost of USD 28,465 across the entire district (22 sub-counties). There are opportunities to finance CSC activities within the available funding streams; for example, leveraging sub-county and district budgets to support operational costs and the existing political will to enhance accountability through the constituency assembly meetings.

\section{Supplementary Information}

The online version contains supplementary material available at https://doi. org/10.1186/s12939-020-01335-9.

Additional file 1: Table S1: Changes in the CSC implementation. Table S2: Detailed CSC Operational Costs. Table S3: Consolidated Health Economic Evaluation Reporting Standards - CHEERS Checklist

Additional file 2: Designing for Scale and Taking Scale to Account: Lessons from a community score card project in Uganda.

Additional file 3: Community score cards and citizen report cards in Uganda; What facilitates and constrains implementation?

\section{Abbreviations}

DFID: Department for international development; FHS: Future health systems research program consortium; MakSPH: Makerere University school of public health; CSC: Community score card; MNH: Maternal and newborn health; VHT: Village health teams; DHT: District health team; WHO: World health Organization; DHO: District health office(r)

\section{Acknowledgements}

The authors would like to acknowledge the helpful review and feedback provided by Chrispus Mayora, Ligia Paina, Natalia Alfonso during the 
development of this manuscript. We also acknowledge the support provided by Christine Aanyu in identification of data inputs used in this study.

\section{Authors' contributions}

All authors contributed to the collation of documents and data used to inform this paper. AS drafted the initial manuscript based on the inputs received from the author team. EEK provided overall guidance and support for the paper, as well as detailed comments on all drafts. EBN, RRA and EEK participated in scoring meetings within the implementation district, contributed to the collation of literature and project documents and provided edits and comments on all drafts. AS, EBN, RRA and EEK did the analysis for the paper. All authors read and approved the final version of the manuscript.

\section{Funding}

The project was supported by DFID through the Future Health Systems (FHS) Consortium program under the Award Number HRPC09 Delivering Effective Health Services. The content of this manuscript is solely the responsibility of the authors and does not necessarily represent the official views of the DFID. We also acknowledge the Kibuku district administration, the research assistants and our study participants.

\section{Availability of data and materials}

Data sharing is not applicable to this article as no datasets were generated or analyzed during the current study.

\section{Ethics approval and consent to participate}

Ethical approval was obtained from the Makerere University School of Public Health Higher Degrees Research and Ethics Committee (MakSPH HDREC) and the Uganda National Council of Science and Technology (UNCST), study number SS 4323.

\section{Consent for publication}

Not applicable.

\section{Competing interests}

The authors declare that they have no competing interests.

Received: 25 May 2020 Accepted: 26 November 2020

Published online: 02 January 2021

\section{References}

1. Ho LS, Labrecque G, Batonon I, Salsi V, Ratnayake R. Effects of a community scorecard on improving the local health system in eastern Democratic Republic of Congo: qualitative evidence using the most significant change technique. Confl Heal. 2015;9(1):27.

2. George A. Using accountability to improve reproductive health care. Reprod Health Matters. 2003:11(21):161-70.

3. Mafuta EM, Dieleman MA, Hogema LM, Khomba PN, Zioko FM, Kayembe PK, et al. Social accountability for maternal health services in Muanda and Bolenge health zones, Democratic Republic of Congo: a situation analysis. BMC Health Serv Res. 2015;15(1):514.

4. Mutale W, Stringer J, Chintu N, Chilengi R, Mwanamwenge MT, Kasese N, et al. Application of balanced scorecard in the evaluation of a complex health system intervention: 12 months post intervention findings from the BHOMA intervention: a cluster randomised trial in Zambia. PLoS One. 2014; 9(4):e93977.

5. Blake C, Annorbah-Sarpei NA, Bailey C, Ismaila Y, Deganus S, Bosomprah S, et al. Scorecards and social accountability for improved maternal and newborn health services: a pilot in the Ashanti and Volta regions of Ghana. Int J Gynecol Obstet. 2016;135(3):372-9.

6. Edward A, Osei-Bonsu K, Branchini C, Shah Yarghal T, Arwal SH, Naeem AJ. Enhancing governance and health system accountability for people centered healthcare: an exploratory study of community scorecards in Afghanistan. BMC Health Serv Res. 2015;15(1):299.

7. Osrin D, Das S, Bapat U, Alcock GA, Joshi W, More NS. A rapid assessment scorecard to identify informal settlements at higher maternal and child health risk in Mumbai. J Urban Health. 2011;88(5):919-32

8. Yilla M, Nam SL, Adeyemo A, Kargbo SA. Using scorecards to achieve facility improvements for maternal and newborn health. Int J Gynecol Obstet. 2014;127(1):108-12.
9. Gullo S, Galavotti C, Altman L. A review of CARE's community score card experience and evidence. Health Policy Planning. 2016;31(10):1467-78.

10. Joshi A. Do they work? Assessing the impact of transparency and accountability initiatives in service delivery. Dev Policy Rev. 2013:31:s29-48.

11. Martin Hilber A, Blake C, Bohle LF, Bandali S, Agbon E, Hulton L. Strengthening accountability for improved maternal and newborn health: a mapping of studies in sub-Saharan Africa. Int J Gynecol Obstet. 2016;135(3):345-57.

12. Bennett S, Mahmood SS, Edward A, Tetui M, Ekirapa-Kiracho E. Strengthening scaling up through learning from implementation: comparing experiences from Afghanistan, Bangladesh and Uganda. Health Res Policy Syste. 2017;15(2):108.

13. Misra V. Pilot study 1, Andhra Pradesh. India: Improving Health Services through Community Scorecards. Learning Notes, Social Accountability Series; 2007.

14. Gaventa J, McGee R. The impact of transparency and accountability initiatives. Dev Policy Rev. 2013;31:s3-s28.

15. Björkman $M$, Svensson J. Power to the people: evidence from a randomized field experiment on community-based monitoring in Uganda. Q J Econ. 2009;124(2):735-69.

16. Ekirapa-Kiracho E, Apolot R, Kiwanuka S. Which contextual factors facilitate successful implementation of community score cards in Uganda? 2018.

17. UNICEF. Annual results report 2017. New York, USA: United Nations Children's Fund; 2018.

18. Ministry of Health. Implementation Guide for Uganda's Reproductive Maternal, Newborn and Child Health Balanced Score Card. Kampala, Republic of Uganda. 2015.

19. UBOS. The National Population and housing census 2014 - Main report. Uganda Bureau of Statistics: Kampala, Uganda; 2016.

20. Namusoke Kiwanuka S, Akulume M, Tetui M, Muhumuza Kananura R, Bua J, Ekirapa-Kiracho E. Balancing the cost of leaving with the cost of living: drivers of long-term retention of health workers: an explorative study in three rural districts in Eastern Uganda. Glob Health Action. 2017;10(sup4):1345494.

21. Wambi M, Kagoda AM, Mugagga AM, Christopher W. Teachers' pedagogical competences and pupils' academic performance in primary schools in Kibuku District, Uganda.

22. Apolot RR, Ekirapa E, Waldman L, Morgan R, Aanyu C, Mutebi A, et al. Maternal and newborn health needs for women with walking disabilities; "the twists and turns": a case study in Kibuku District Uganda. Int J Equity Health. 2019:18(1):43.

23. UBOS. Uganda subcounties 2014. In: Uganda Bureau of Statistcs. Kampala, Uganda: Dataset ed; 2014.

24. Kigozi FN, Kizza D, Nakku J, Ssebunnya J, Ndyanabangi S, Nakiganda B, et al. Development of a district mental healthcare plan in Uganda. Br J Psychiatry. 2016:208(s56):s40-s6.

25. Katende D, Mutungi G, Baisley K, Biraro S, Ikoona E, Peck R, et al. Readiness of Ugandan health services for the management of outpatients with chronic diseases. Tropical Med Int Health. 2015;20(10):1385-95.

26. Müller-Nordhorn J, Brüggenjürgen B, Böhmig M, Selim D, Reich A, Noesselt $\mathrm{L}$, et al. Direct and indirect costs in a prospective cohort of patients with pancreatic cancer. Aliment Pharmacol Ther. 2005;22(5):405-15.

27. Walker D. Cost and cost-effectiveness guidelines: which ones to use? Health Policy Plan. 2001;16(1):113-21.

28. Cunnama L, Sinanovic E, Ramma L, Foster N, Berrie L, Stevens W, et al. Using top-down and bottom-up costing approaches in LMICs: the case for using both to assess the incremental costs of new technologies at scale. Health Econ. 2016:25:53-66.

29. Levin HM. Cost-effectiveness: a primer. London: Sage publications; 1983.

30. Levin HM, Belfield C. Guiding the development and use of cost-effectiveness analysis in education. J Res Educ Effectiveness. 2015;8(3):400-18.

31. WorldBank. Official exchange rate (LCU per US\$, period average): The World Bank; ; 2019 [Available from: http://data.worldbank.org/indicator/PA.NUS.fCrf.

32. Joshi A, Houtzager PP. Widgets or watchdogs? Conceptual explorations in social accountability. Public Manag Rev. 2012;14(2):145-62.

33. Gullo S, Galavotti C, Sebert Kuhlmann A, Msiska T, Hastings P, Marti CN. Effects of the community score card approach on reproductive health service-related outcomes in Malawi. PLoS One. 2020;15(5):e0232868.

34. Arkedis J, Creighton J, Dixit A, Fung A, Kosack S, Levy D. Can transparency and accountability programs improve health? Experimental evidence from Indonesia and Tanzania. 2019.

35. Razavi SD, Kapiriri L, Abelson J, Wilson M. Who is in and who is out? A qualitative analysis of stakeholder participation in priority setting for health in three districts in Uganda. Health Policy Plan. 2019;34(5):358-69. 
36. Patel D, Shah P, Islam M. Impact of social Accountability mechanisms on achieving service delivery and health development outcomes in Satara District, Maharashtra, India. Washington, DC: The World Bank; 2009.

37. Kabunga NS, Mogues T, Bizimungu E, Erman A, Van Campenhout B. The state of public service delivery in Uganda: report of a baseline survey: Intl food policy res Inst; 2016.

38. Howard J, López Franco E, Shaw J. Navigating the pathways from exclusion to accountability: from understanding intersecting inequalities to building accountable relationships. 2018

39. Post D, Agarwal S, Venugopal V. Rapid feedback: the role of community scorecards in improving service delivery. 2014.

40. Makosa D, Takayanagi N. Improving rural livelihood through NERICA farming: an inquiry into Najja Sub-county in Central Uganda. Asian J Agric Rural Dev. 2014;4(393-2016-23927):59-73.

41. Mukwaya P, Bamutaze Y, Mugarura S, Benson T. Rural-urban transformation in Uganda. J Afr Dev. 2012;14(2):169-94.

42. Nalwadda G, Mirembe F, Tumwesigye NM, Byamugisha J, Faxelid E. Constraints and prospects for contraceptive service provision to young people in Uganda: providers' perspectives. BMC Health Serv Res. 2011;11(1):220.

43. Sanders GD, Neumann PJ, Basu A, Brock DW, Feeny D, Krahn M, et al. Recommendations for conduct, methodological practices, and reporting of cost-effectiveness analyses: second panel on cost-effectiveness in health and medicine. Jama. 2016;316(10):1093-103.

44. Ismail A, Suddin LS, Sulong S, Ahmed Z, Kamaruddin NA, Sukor N. Economic burden of managing type 2 diabetes mellitus: analysis from a teaching Hospital in Malaysia. Indian J Public Health. 2017:61(4):243.

45. Huter K, Kocot E, Kissimova-Skarbek K, Dubas-Jakóbczyk K, Rothgang H. Economic evaluation of health promotion for older people-methodological problems and challenges. BMC Health Serv Res. 2016;16(5):-328.

\section{Publisher's Note}

Springer Nature remains neutral with regard to jurisdictional claims in published maps and institutional affiliations.

Ready to submit your research? Choose BMC and benefit from:

- fast, convenient online submission

- thorough peer review by experienced researchers in your field

- rapid publication on acceptance

- support for research data, including large and complex data types

- gold Open Access which fosters wider collaboration and increased citations

- maximum visibility for your research: over $100 \mathrm{M}$ website views per year

At $\mathrm{BMC}$, research is always in progress.

Learn more biomedcentral.com/submissions 